\title{
Div 563
}

NBSIR 81-2418

\section{Fabrication of Ultra-Drawn Thick PVDF Transducers}

U.S. OEPARTMENT OF COMMERCE National Bureau of Standards Center for Materiais Science

Polymer Science and Standards Division

Washington, DC 20234

December 1981

Final Report

Prepared for:

Naval Ocean Systems Center

San Diego. California 92152 



\title{
FABRICATION OF ULTRA-DRAWN THICK PVDF TRANSDUCERS
}

\author{
A. J. Bur and A. K. Tsao
}

U.S. DEPARTMENT OF COMMERCE

National Bureau of Standards

Center for Materials Science

Polymer Science and Standards Division

Washington, DC 20234

December 1981

Final Report

Contract No. N66001-81-MP00024

Charles Hicks, Contract Officer

Reproduction in whole or in part is permitted for any purpose of the United States Government.

This document has been approved for public release and sale; its distribution is unlimited.

Prepared for:

Naval Ocean Systems Center

San Diego, California

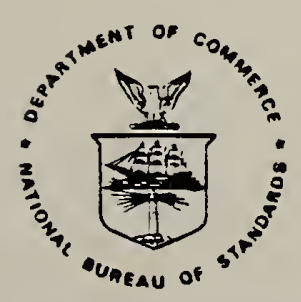

U.S. DEPARTMENT OF COMMERCE, Malcolm Baldrige, Secretary NATIONAL BUREAU OF STANDARDS, Ernest Ambler, Director 

Fabrication of UTtra-Drawn Thick PVDF Transducers

\author{
A. J. Bur and A. K. Tsao \\ Polymer Science and Standards Division \\ Center for Materials Science \\ National Bureau of Standards \\ Washington, D.C. 20234
}

\title{
Abstract
}

Ultra-drawn PVDF (polyvinylidene fluoride) transducers have been fabricated from pellet resin material with thicknesses of $0.23,0.30$ and $0.50 \mathrm{~mm}$. The samples were mechanically ultra-drawn beyond their natural 4:1 draw ratio to a 7:1 ratio in order to enhance the molecular orientation and thereby optimize the piezoelectric activity. The samples were characterized using modulus and $x$-ray measurements which showed that modulus increases with increasing draw ratio and that the crystalline portion of the $7: 1$ drawn material was mostly 3 phase. Ten out of fourteen samples were successfully poled at room temperature with fields ranging from 1.6 to $2.5 \mathrm{MV} / \mathrm{cm}$. The pyroelectric activities ranged from 2.0 to $4.1 \frac{\mathrm{nc}}{\mathrm{cm}^{2} \mathrm{~K}}$ and the hydrostatic piezoelectric coefficients ranged from 8.6 to $15.6 \mathrm{pC} / \mathrm{N}$. 

Introduction

An accepted method of fabricating PVDF transducers is mechanical orientation of sheets or film followed by poling of the sample with fields of $2 \mathrm{MV} / \mathrm{cm}$ or more at room temperature. One reason for mechanical orientation of the sample is to achieve greater breakdown strength and thereby permit the application of high poling fields ${ }^{1}$.

According to studies by Shuford and coworkers ${ }^{2}$ in 1976 and recently by Nix et $a 7^{3}$, the piezoelectric activity of PVDF can be optimized by mechanically ultra-drawing beyond the "natural" 4:1 draw ratio. In the above studies, different techniques of mechanical drawing were used but the properties of the ultra-drawn film were similar. In the first study ${ }^{2}$, a thin film sheet was fed from a storage drum througin an oven at $30^{\circ} \mathrm{C}$ to a take-up drum which rotated at a speed higher than the feed drum. Draw ratios of $6: 1$ could be obtained by rotating the take-up drum six times faster than the feed drum. Typical take-up rates were $30 \mathrm{~m} / \mathrm{min}$. In the second case ${ }^{3}$, Nix et al, using an Instron ${ }^{a}$ mechanical testing machine worked at much slower draw rates and higher temperatures, $0.2 \mathrm{~cm} / \mathrm{min}$ over a temperature range from 80 to $140^{\circ} \mathrm{C}$. Stretching was done in one step, that is, the sample was extended through the yield point, necking and on to strain hardening in the range of draw ratios from $4: 1$ to $8: 1$. In both cases, it was found that for a constant set of poling conditions, the piezoelectric activity increased with increasing draw ratio.

In this project our goal has been to develop a processing technique which can be used to produce and characterize thick ultra-drawn transducers of PVDF without special drawing equipment. The procedures which are described below include compression molding of PVDF samples from pellet resin material, mechanical orientation of the material, characterization of the drawn material using modulus and $x$-ray measur ments, poling the drawn material at high electrical fields and measuring the piezo

a) Identification of a comercial product is made only to facilitate experimental reproducibility and does not imply endorsement by NBS. 
and pyroelectric activity. The nominal sample thicknesses which we desired were $0.23,0.30$, and $0.5 \mathrm{~mm}(9,12$ and $20 \mathrm{mils})$.

\section{Preparation of Samples}

The raw material used for fabricating our thick specimens was Solef 1012 PVDF in pellet form ${ }^{2}$. Solef 5008 powder was also used but this material was found to be unsatisfactory because it tended to stick tenaciously to the mold surface. The pellet material was formed into disks, $14 \mathrm{~cm}\left(5 \frac{1}{2} \mathrm{in}.\right)$ in diameter and of appropriate thickness, by compression molding under vacuum at $190^{\circ} \mathrm{C}$. The mold, which is shown schematically in Figure 1 , has two cylindrical stainless steel plates whic are the mold surfaces. For convenient handling the stainless steel plates are attached to aluminum backing plates. A vacuum seal is provided by o-ring seals be. tween the steel plates and an aluminum collar which surrounds the steel plates. A vacuum port, situated at the side of the collar, provides a connection to the vacuu pump.

During molding, the two steel plates are.held apart by a stainless steel separation ring, the thickness of which determines the thickness of the molded disk. Three sizes of separation rings were used. The rings, each with an ID of $14 \mathrm{~cm}$ ( $5 \frac{7}{2}$ in.) and an OD of $16 \mathrm{~cm}$ ( $6 \frac{7}{4}$ in.), had thicknesses of $0.96 \mathrm{~mm}$ (38 mils), $1.27 \mathrm{~mm}(50 \mathrm{mils})$, and $1.88 \mathrm{~mm}(74 \mathrm{mils})$. These rings respectively yielded final sample thicknesses after ultra-drawing of $0.23 \mathrm{~mm}$ (9 mils), $0.30 \mathrm{~mm}$ (12 mils), and $0.50 \mathrm{~mm}(20 \mathrm{mi} 1 \mathrm{~s})$.

Prior to compression of a sample, the mold, o-rings, o-ring seats and collar were cleaned with ethanol. After the o-rings and collar were treated with silicone vacuum grease, the o-rings were positioned in their seats and the collar was set in place around the bottom plate.

The amount of PVDF material placed in the mold was in excess of the mold volume in order to ensure that no voids remained unfilled. This resulted in a sample disk which was approximately 10\% larger than the separation ring. The mass pellet resin used with each separation ring was: $38 \mathrm{gm}$ for the $38 \mathrm{mil}$ ring; $50 \mathrm{gm}$ 
for the $50 \mathrm{mil}$ ring and $71 \mathrm{gm}$ for the $74 \mathrm{mil}$ ring. After the pellets were placed in the mold, the mold was connected to the vacuum pump and placed in a hydraulic press with top and bottom in contact with the heated platens of the press but not under pressure.

The hydraulic press has platens with surface dimensions of $30.5 \mathrm{~cm} \times 30.5 \mathrm{~cm}$ (12 in. square). Temperature controlled heaters and cooling coils are embedded in the platens so that the temperature can be set in the range from $50{ }^{\circ} \mathrm{C}$ to $400{ }^{\circ} \mathrm{C}$ with $\pm 5{ }^{\circ} \mathrm{C}$ control. The cooling coils, which are connected to a water line, were used to quickly cool the platens from the high molding temperature to room temperature.

If the platens of the press were preheated to $190^{\circ} \mathrm{C}$, then it would take approximately 30 minutes for the sample to reach its melting temperature. The pressure which we usually achieved was 50-60 um of $\mathrm{Hg}(6.65-8.0 \mathrm{~Pa})$; higher pressures, up to $200 \mathrm{um}(26.6 \mathrm{~Pa})$, were also found to yield satisfactory results.

The temperature of the interface between platen and mold was monitored by a copper-constantan thermocouple probe which fit into a groove cut into the aluminum facing of the mold. When this temperature reached $175^{\circ} \mathrm{C}$, melting of the sample soon followed and this was noted by a slight decrease $(2 \mathrm{~mm})$ in the separation between the top and bottom plates of the mold. When the temperature of the interface reached $190{ }^{\circ} \mathrm{C}$, the mold was placed under a pressure of $1.9 \times 10^{6} \mathrm{~N} / \mathrm{m}^{2}$ (265 1 bs. $/$ in. $^{2}$ ). Under constant pressure, the temperature was held at $190{ }^{\circ} \mathrm{C}$ for 10 minutes after which time the heaters were turned off and the water line was opened to the cooling coils. Care was taken to dissipate safely the steam which was generated by the hot platens. Using the cooling coils it was possible to change the temperature of the interface from $190^{\circ} \mathrm{C}$ to $50^{\circ} \mathrm{C}$ in 8 minutes.

It was found that by quickly cooling the mold under pressure, we were able to produce samples with uniform surfaces. By contrast, samples slowly cooled under pressure, usually had surface pock marks and streaks which we attributed to non-uniform temperature distribution of the stainless steel plates as the mold was cooling through 
the freezing point of the polymer.

In order to remove the sample from the mold, the plates were separated using a set of three $0.6 \mathrm{~cm}$ ( $\frac{3}{4}$ in.) diameter rods which were inserted through holes in the overlapping edge of the top plate and reached to the overlapping bottom edge (Figure With the mold set up on blocks in the press, pressure was applied to the rods forcing the plates to separate.

Mechanical Drawing

The sample to be mechanically oriented was sliced from the center of the molded disk in the shape of a rectangle $7 \mathrm{~cm}$ wide by $14 \mathrm{~cm}$ long. Gauge marks were penned on the sample for the purpose of measuring subsequent draw ratios. Mechanical drawing was carried out using an Instron testing machine which was adapted with a temperature control jacket ${ }^{\mathrm{a}}$.

Secure and tight grips on the sample are essential for uniform drawing. The grips which we used were hardened steel flats with surface dimensions of $7.6 \mathrm{~cm}$ wide $\times 5.1 \mathrm{~cm}$ high $\left(3 \mathrm{in} . \times 2\right.$ in.). The flats were connected to a $3.8 \mathrm{~cm}$ (1 $1 \frac{1}{2}$ in.) diameter bolt which was threaded through the yoke of the grip assembly. The sample was placed in the grips with sheets of fine grit sand paper, no. 400 , between the sample and grip surfaces with the abrasive side against the sample. A sample surface area as large as possible was placed between the grips, i.e. $5.1 \mathrm{~cm}$ (2 in.) from each end of the sample was kept in the grips. The grip bolts were tightened manually with as large a torque as possible by using a ratchet wrench with a $30 \mathrm{~cm}$ handle. As the temperature of the oven was raised, the sample grips were retightened at $120{ }^{\circ} \mathrm{C}$.

Because extension of the sample was limited by the size of the oven, drawing was carried out in two steps: first, a $15 \mathrm{~cm}$ length of $4: 1$ drawn material was obtained by drawing at a rate of $0.25 \mathrm{~cm} / \mathrm{min}$. at $140{ }^{\circ} \mathrm{C}$; second, this $15 \mathrm{~cm}$ sample was reclamped in the Instron and extended at a rate of $0.12 \mathrm{~cm} / \mathrm{min}$. at $140{ }^{\circ} \mathrm{C}$. The initial grip separation for the 4:1 draw was $2.54 \mathrm{~cm}$ and the final separation was $15.2 \mathrm{~cm}$. For the $7: 1 \mathrm{draw}$, the initial grip and final grip separations were $3.81 \mathrm{~cm}$ and $10.2 \mathrm{~cm}$. These grip separations do not correspond exactly to $4: 1$ and $7: 1$ ratios 
because there was normally some sample slippage out of the grips. Routinely, we were able to obtain draw ratios of $6.5: 1$ to $7: 1$, but, drawing beyond $7: 1$ usually resulted in transverse fracture or a split in the direction of orientation.

Characteristic load vs extension curves are shown in Figure 2. In Figure 2(a) are shown the data for the natural 4:1 draw ratio. The sample begins to neck at the maximum load and then proceeds to yield over the horizontal portion of the curve where the load is constant with extension. By contrast, in Figure 2(b), which is for ultra-drawing beyond the $4: 1$ ratio, the load is continually increasing with extension. Since the cross sectional area of the sample decreases with extension during ultra-draw, a continually increasing load indicates that the Young's modulus of the sample is increasing also.

It was found that ultra-drawing unoriented PVDF to a draw ratio of $7: 1$ caused a thickness reduction by a factor of 4.5 . That is, in order to obtain an ultradrawn sample of $0.30 \mathrm{~mm}(12 \mathrm{mils})$ thickness, the unoriented starting material had to be $1.37 \mathrm{~mm}$ (54 mils) thick. The reduction in the width of the sample was by a factor of 1.6 .

Poling Procedures

In order to avoid flashover and corona problems at the high poling voltages (45 KV and greater), all poling was carried out under oil in a cell which is sketched in Figure 3. The maximum sample size was limited to the inside diameter of the cell which is $4.4 \mathrm{~cm}$ (1.75 in.). The two ports on the cell are used to introduce silicone oil into the cell under vacuum. $0 i 1$ is pulled through a $20 \mathrm{um}$ pore filter connected to one port by a vacuum line connected to the other. Voltage is applied to the sample via the two $6.3 \mathrm{~mm}$ ( $\left(\frac{\bar{y}}{\mathrm{in}} \mathrm{i}\right.$ ) diameter rods between which the sample is squeezed. During poling, the chamber itself was immersed in a larger transformer oil bath so that corona did not become a problem.

Electrodes were attached to all samples by using silver paint. In order to avoid breakdown due to high fields at the edge of the electrodes, the edges were raised. This was done by encircling the central area of the electrode with a 
raised ring of epoxy. The electrode was then painted on to the epoxy ring. Flashover problems were minimized by having an apron of material extending beyond the electrodes of the sample.

The following poling conditions were used: for the $0.23 \mathrm{~mm}(9 \mathrm{mil})$ specimens, $45 \mathrm{kV}(2 \mathrm{MV} / \mathrm{cm})$ for 1 minute at room temperature; for the $0.30 \mathrm{~mm}(12 \mathrm{mil})$ specimens, $75 \mathrm{kV}(2.5 \mathrm{MV} / \mathrm{cm})$ for 1 minute at room temperature; and for the $0.5 \mathrm{~mm}$ (20 $\mathrm{mil}$ ) specimens, $82 \mathrm{kV}(1.6 \mathrm{MV} / \mathrm{cm})$ for 1 minute at room temperature. Characterization of Samples

The samples were selectively characterized by modulus and $x$-ray measurements and all successfully poled samples were characterized by their piezo and pyroelectric coefficients.

\section{a. Modulus Measurements}

The Young's modulus was obtained from a stress measurement at $10 \mathrm{sec}$ in a stress relaxation experiment. In this experiment, the sample is held at a constant deformation while a load is applied in the direction of orientation and the stress is monitored as a function time. It was found that the stress-strain behavior was linear up to $3 \%$ strain for oriented specimens but only up to $1 \%$ for the one unoriented sample. The samples for the modulus measurements were die cut strips which were $0.2 \mathrm{~cm}$ in width by $5 \mathrm{~cm}$ long with thickness in the range 0.1 to $0.5 \mathrm{~mm}$. The accuracy of the modulus measurement is estimated to be $\pm 5 \%$.

The results of the modulus measurements are shown in Table I and Figure 4. The ultra-drawn sample, 24 , with a draw ratio of $7: 1$, has a Young's modulus of $3.1 \mathrm{GPa}$. This is in good agreement with the measurements of Nix et a $7^{3}$ and is a factor of 1.8 greater than the modulus for the unoriented material and $20 \%$ higher than the modulus of sample 27 for which the draw ratio is $4: 1$.

\section{b. X-ray Mea surements}

Wide angle $x$-ray measurements were made using CuKa radiation and a graphite monochromator. X-ray patterns were recorded in reflection with the $x$-ray beams perpendicular to axis of draw and in transmission with the axis of draw tilted at 
an angle with respect to the beam. The sample was tilted in order to obtain $(001)$ reflections of the $\beta$ phase and (002) of the $\alpha$ phase. The ratio of the intensity of the $\alpha$ and $\beta$ reflections along with structure factors ${ }^{4}$ of these reflections were considered in making an estimate of the relative amounts of $\alpha$ and $\beta$ phase present.

In Figure 5 , plots of $x$-ray intensity $v s .2 \theta$ for $4: 1$ and $7: 1$ drawn samples are shown. These plots are for the transmission experiment in which (001) planes are detected. It is we11-known that stretching PVDF to $4: 1$ draw ratio at temperatures above $100^{\circ} \mathrm{C}$ results in $\alpha$ phase as shown in Figure $5(a)$. However, as shown previously; ${ }^{2,3}$ ultra-drawing to ratios higher than $4: 1$ produces $\beta$ phase materia? as seen in Figure 5(b). Considering the relative magnitudes of the $002 \alpha$ and $001 \beta$ peaks in Figure $5(b)$ and the relative structure factors ${ }^{4}$, it is estimated that $B$ phase is $90 \%$ of the crystalline phase.

c. Pyro and Piezcelectric Measurements

The pyroelectric and piezoelectric activities of these samples were measured in a temperature pressure ce!l which has been previously described. ${ }^{5}$ In this measurement, current is generated by the transducer in proportion to the change in pressure or temperature with time. The estimated accuracy of pyroelectric and piezoelectric coefficients is estimated to be $\pm 5 \%$.

In Table II we have listed the hydrostatic piezoelectric coefficient $d_{h}$ and the pyroelectric coefficient Py along with other information for all samples we have measured thus far. The prime mark on the sample designation indicates that the data for these samples has been corrected for the fringing contribution by punching out the electroded portion and measuring it separately from the rest of the sample. The data for the other samples has not been corrected and the apparent high numbers should be considered with caution.

Discussion

Our two-step drawing procedure, as it is traced out in Figure 2, contrasts with the methods previously published. ${ }^{2,3}$ Although Nix et a ${ }^{3}$ took the precaution 

to cut dumbbell shaped samples for drawing experiments, we have found that thick rectangular samples could be drawn without transverse fracture or tearing at the grip. While some slippage from the grip occurred and probably neutralized the high stress there, the final product was not affected by the initial rectangular shape.

In Figure $2(b)$ the change in slope at 10\% extension was observed for a 11 specimens. It is a consequence of the two stage drawing procedure. After a sample has been drawn to $4: 1$ ratio and it is released from the clamps, its length retracts by approximately $10 \%$. When this sample is reclamped in the Instron, the initial extension retraces the $10 \%$ retraction until the load reaches a level corresponding to the yield load of Figure $2(a)$. At this point, drawing beyond the $4: 1$ ratio commences as stress on the sample continues to increase with extension. As mentioned above, the increasing stress with decreasing width and thickness dimensions means that the modulus of the sample is also increasing. We interpret this to mean that energy is being used to orient and extend the molecular structure and that yield or plastic flow is not occurring.

As shown by Shuford et $\mathrm{al} \mathrm{l}^{2}$ and $\mathrm{Nix}$ et $\mathrm{a} ?^{3}$, a stress induced crystalline phase transition from $\alpha$ to $B$ phase occurs as the draw ratio increases from $4: 1$ to $7: 1$. Their data indicates that the $\beta$ phase grows at the expense of the $\alpha$ phase and there appears to be no increase in crystallinity. While the $x$-ray patterns show that orientation occurs in the crystalline regions, the increase in modulus during ultra drawing indicates an increase in the number of tie molecules in the amorphous regio and corresponding increase in orientation of the amorphous phase 2,3 . This is sup. ported by birefringence measurements which show a saturation in the crystal orienta tion at $5: 1$ draw ratio ${ }^{2}$.

When the piezo and pyroelectric activities of the punched out samples, the first five listed in Table II, are compared with the data of Nix et al, significant differences can be seen. For the same draw ratio and poling field our pyroelectrip coefficients are $25 \%$ lower than theirs while for $d_{h}$ there is no significant differ 
ence. We do not know the source of this difference other than to point out that the time scale of the two measurements was different by a factor of 20 . Our experiment employed a temperature change from $23{ }^{\circ} \mathrm{C}$ to $25{ }^{\circ} \mathrm{C}$ at the rate of $0.6{ }^{\circ} \mathrm{C} / \mathrm{min}$ whereas $\mathrm{Nix}$ et al used a large temperature change from $10{ }^{\circ} \mathrm{C}$ to $30^{\circ} \mathrm{C}$ at a rate of $0.2^{\circ} \mathrm{C} / \mathrm{sec}$. We have assessed our experiment considering these factors and can find no source of error to account for the $25 \%$ difference. Conciusions

The fabrication of thick PVDF ultra-drawn transducers can be achieved by using straight forward drawing and poling procedures. Drawing was done in two steps: the sample was first drawn to its natural 4:1 draw ratio and then reclamped and drawn to a ratio of $7: 1$. It was not necessary to use a dumbbell shaped sample; a rectangular shape was found to be adequate and did not lead to tearing or fracture at the grip.

Poling, which was done in $0 i 1$ at room temperature for 1 minute, was carried out successfuliy as long as edges of the electrodes were raised so that high edge fields were avoided. Ten out of fourteen samples were poled at fields in the range 1.6 to $2.5 \mathrm{MV} / \mathrm{cm}$. 


\section{Acknowledgements}

The authors wish to acknowledge the assistance of Mr. Chester A. Harding and Drs. John M. Crissman and Martin Misakian for their help with x-ray, modulus and poling experiments. The support of the Naval Ocean System Center is also gratefully acknowledged. 


\section{References}

1. A. J. Bur, Polymer, 22, 1288 (1981).

2. R. J. Shuford, A. F. Wilde, J. J. Ricca, and G. R. Thomas, Poly. Eng. and Sci. 16, 25 (1976).

3. E. L. Nix, L. Holt, J. C. McGrath and I. M. Ward, Ferroelectrics 32, 103 (1981).

4. R. Hasegawa, Y. Takahashi, Y. Chatani and H. Tadokora, Polymer J. 3, 600 (1972).

5. M. G. Broadhurst, G. Malmberg, F. I. Mopsik and W. P. Harris in "Electret, Charge Storage and Transport in Dielectrics," ed. by M. M. Periman, The Electrochemical Soc., Princeton, NJ, p. 492, (1973). 
Modulus ${ }^{b}$

Sample

26

27

24
Condition draw ratio unoriented

$4: 1$

$7: 1$
Young's Modulus

$\mathrm{GPa}$

1.7

2.6

3.1

botained from a stress relaxation experiment at 10 seconds 


\section{Sample}

$15 d^{\prime}$

$15 e^{\prime}$

$23 b^{\prime}$

$24 b^{\circ}$

$18 a^{\circ}$

$23 a$

29

$30 \mathrm{~b}$

16

$31 b$ $\frac{\text { Thickness }}{\mathrm{mm}}$

0.24

0.24

0.22

0.21

0.25

0.22

0.33

0.30

0.52

0.53
Draw Ratio

$6.5: 1$

$6.5: 1$

$7: 1$

$7: 1$

$6.5: 1$

$7: 1$

$7: 1$

$6.5: 1$

2.5

$6: 1$

1.6

1.6

$6.5: 1$

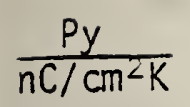

2.62

2.82

2.86

2.75

2.50

2.2

3.5

4.1

2.4

2.0 $\frac{d_{h}}{p C / N}$

15.5

14.5

13.3

15.6

12.2

11.2

15

18

11
8.6 


\section{Figure Captions}

1. A side view of the vacuum compression mold is shown.

2. (a) The trace of a load vs. extension curve for the primary draw to 4:1 draw ratio is shown.

(b) The trace of a load vs. extension curve for the secondary draw from $4: 1$ to $7: 1$ draw ratio is shown.

3. A cross-section view of the poling cell is shown.

4. Stress-strain curves which were obtained from various stress relaxation experiments are shown. $\Delta$, unoriented; 0, 4:1 draw ratio; $\bullet, 7: 1$ draw ratio.

5. X-ray intensity vs. $2 \theta$ for transmission observations are shown. $\theta$ is the angle of reflection. (a) 4:1 draw ratio; (b) $7: 1$ draw ratio. 


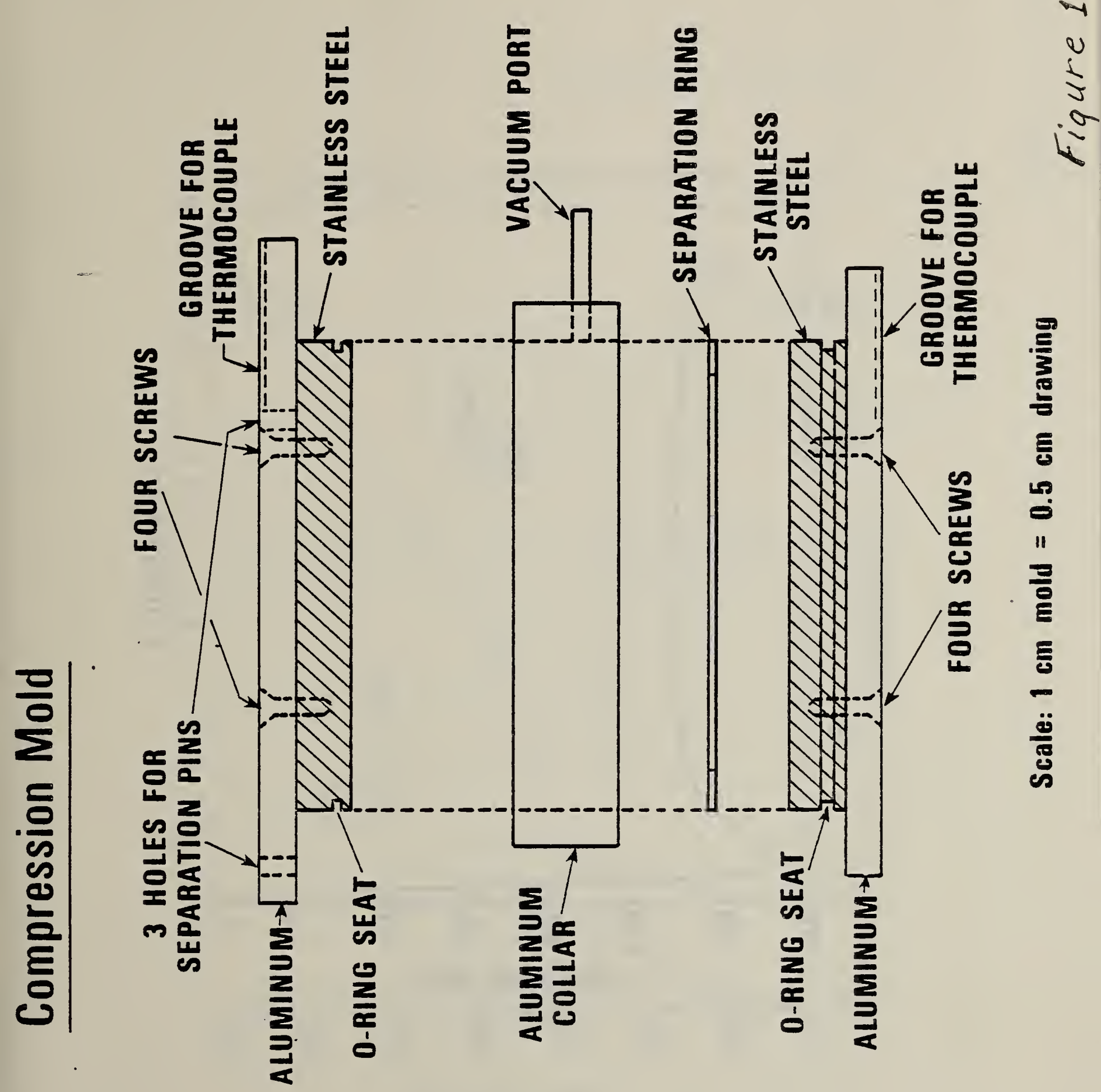




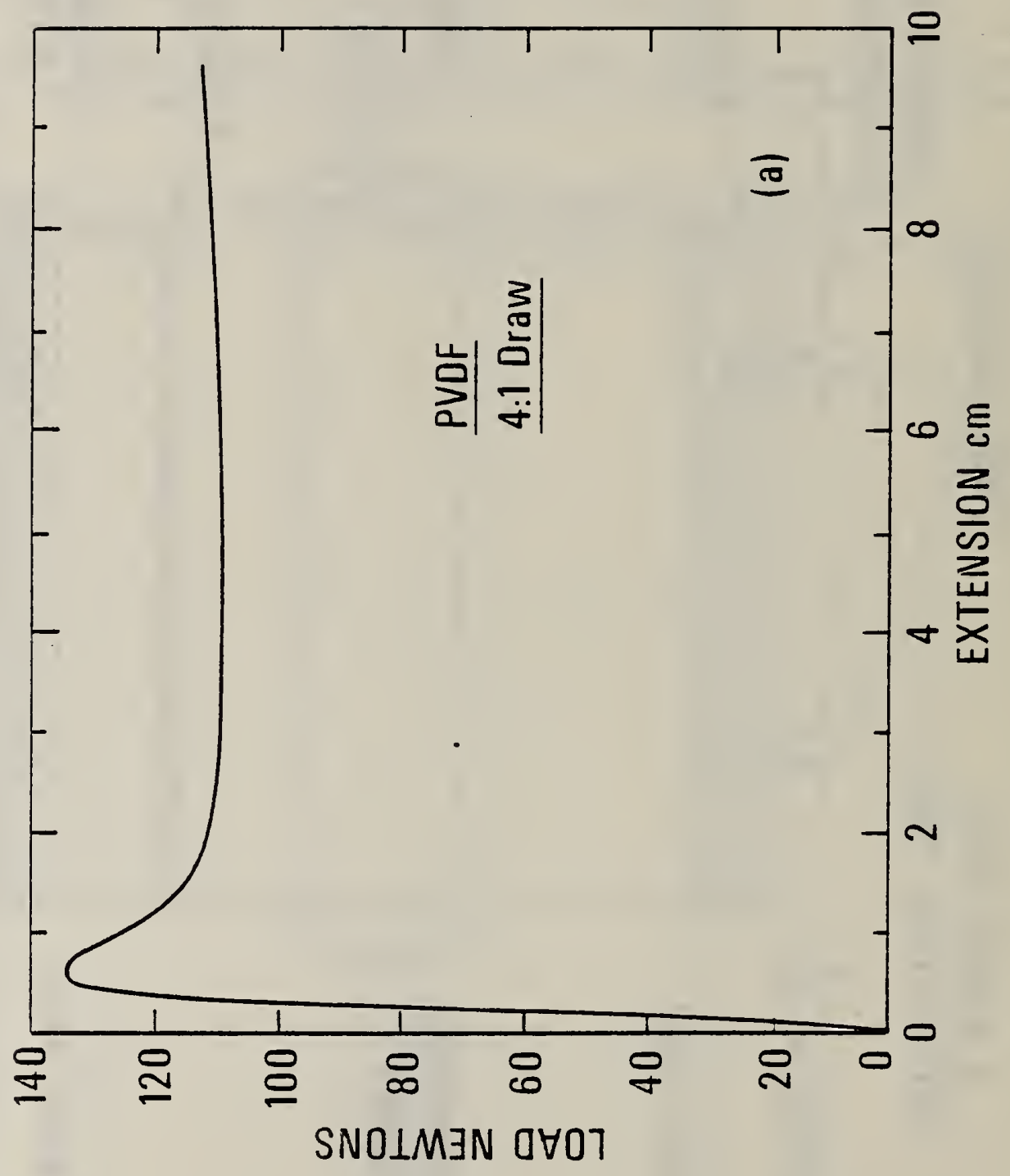




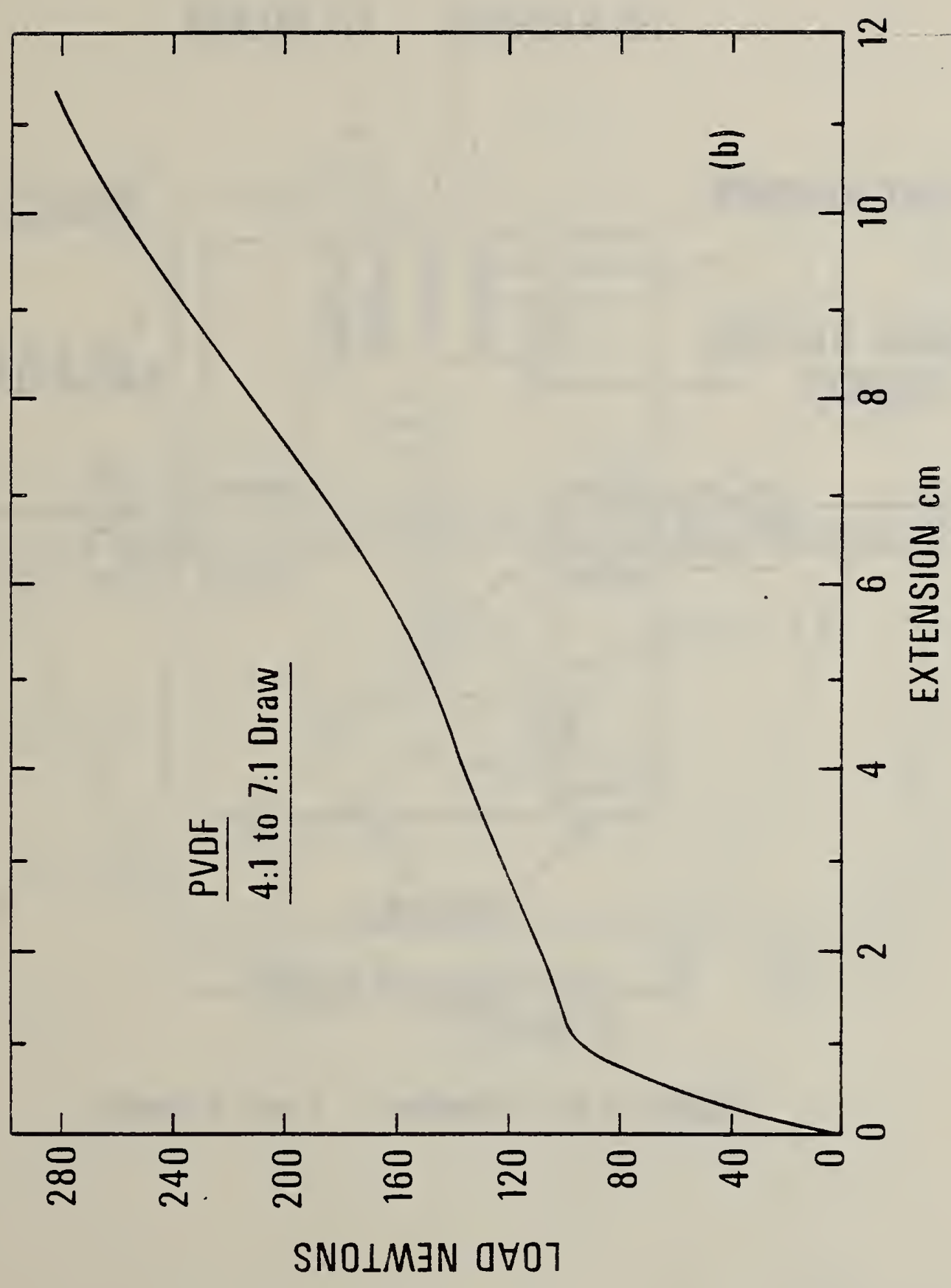




\section{Poling Chamber}

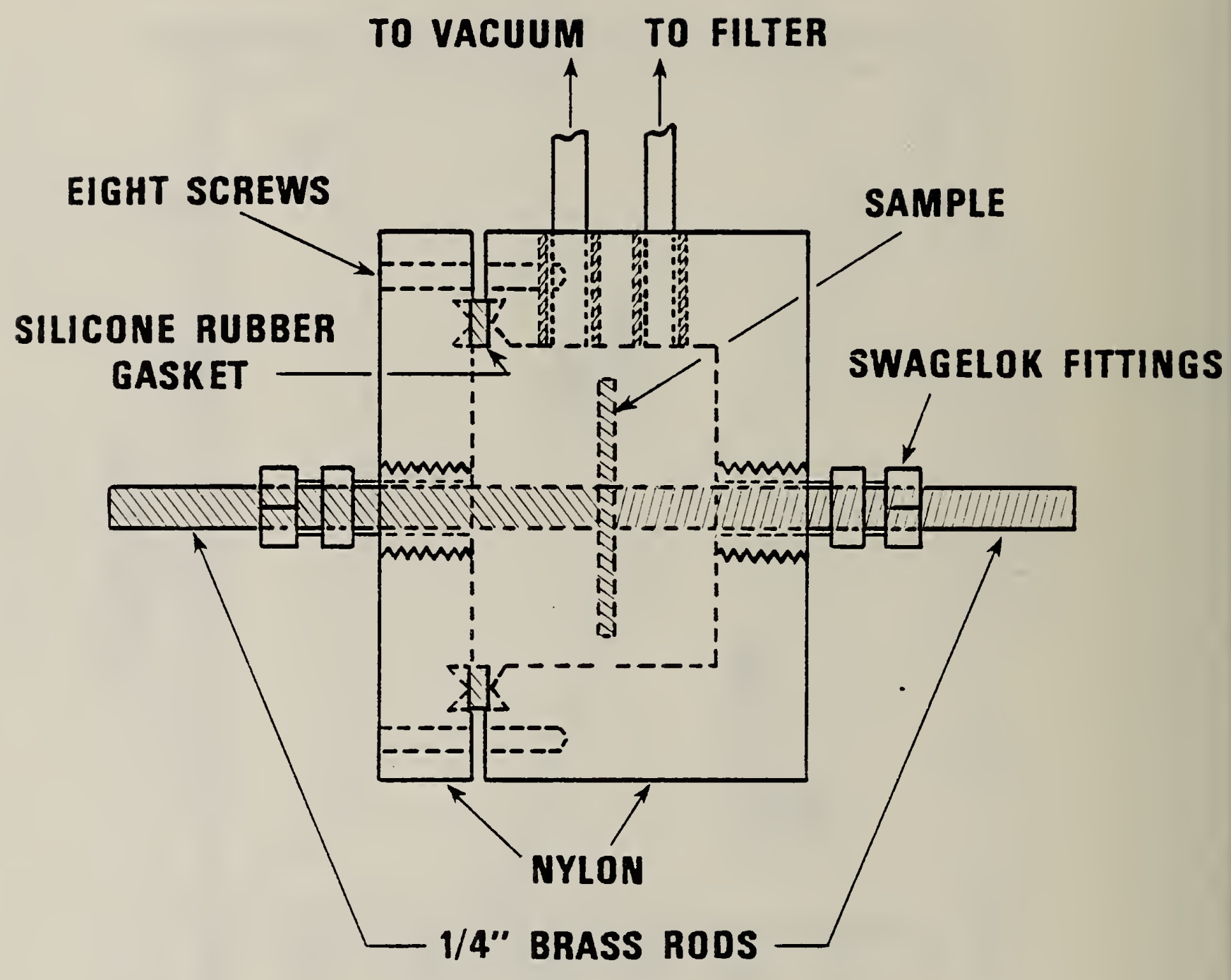

Scale: $1 \mathrm{~cm}$ chamber $=1 \mathrm{~cm}$ drawing 


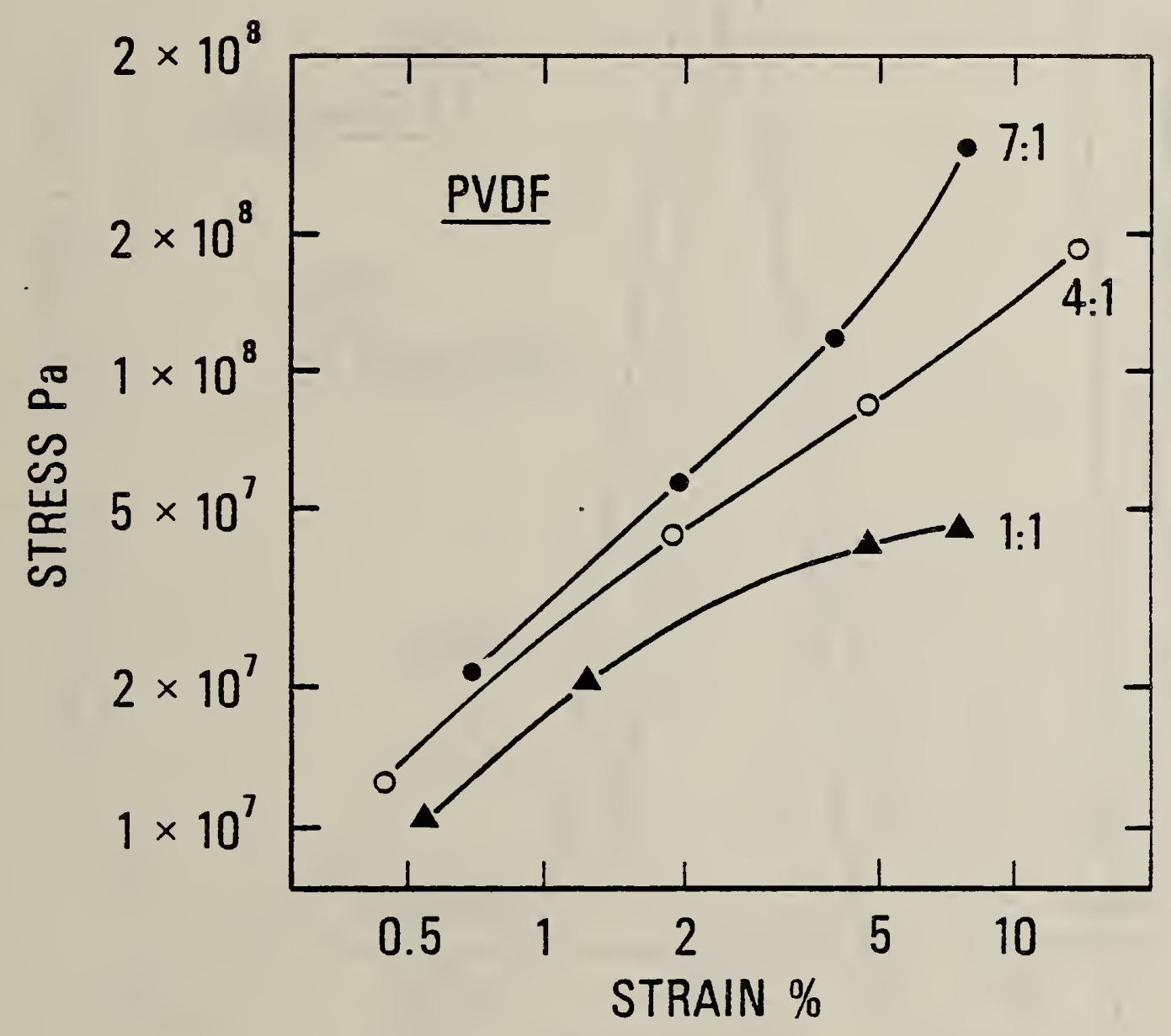

Figure 4 


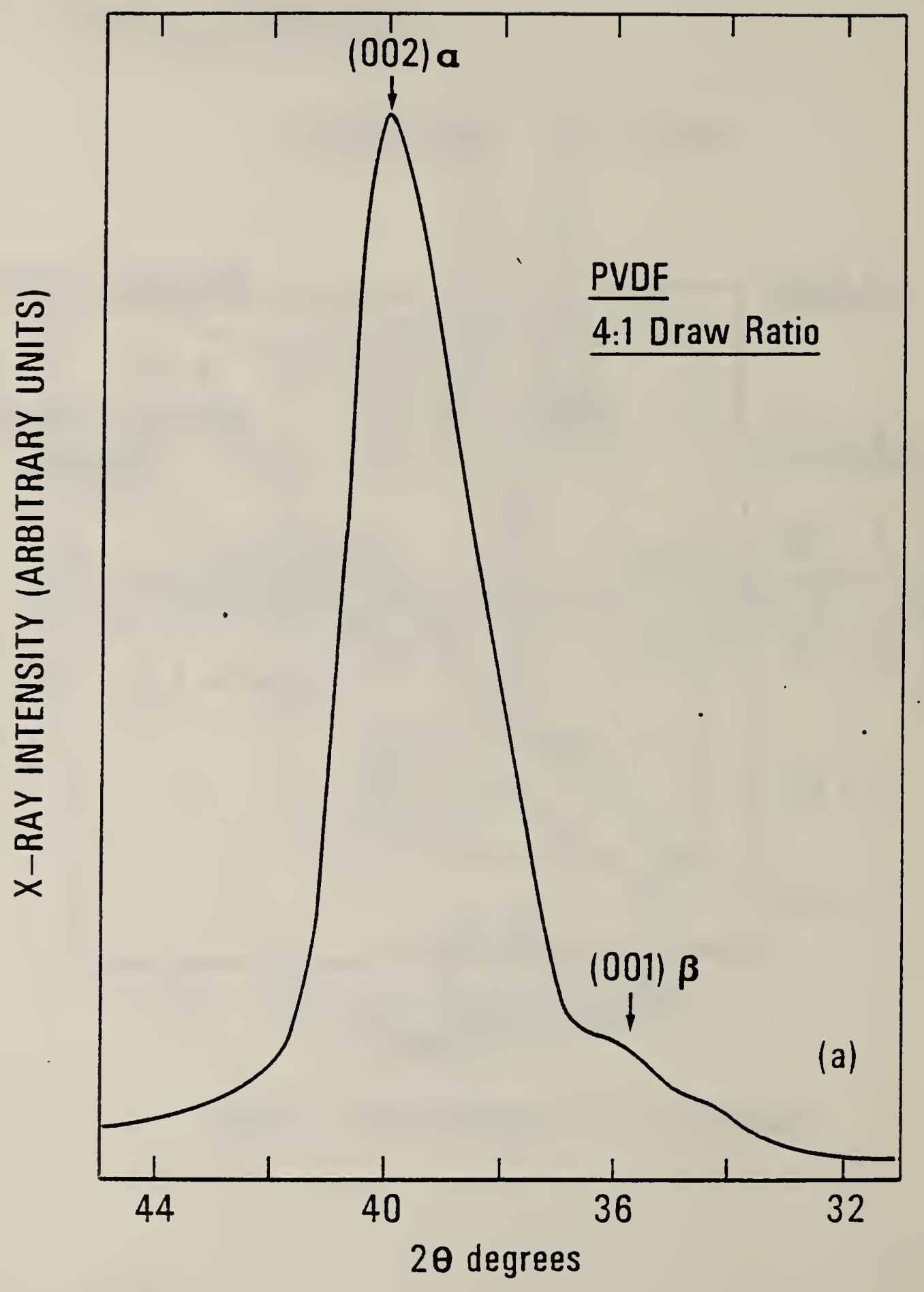

Figure 5(a) 


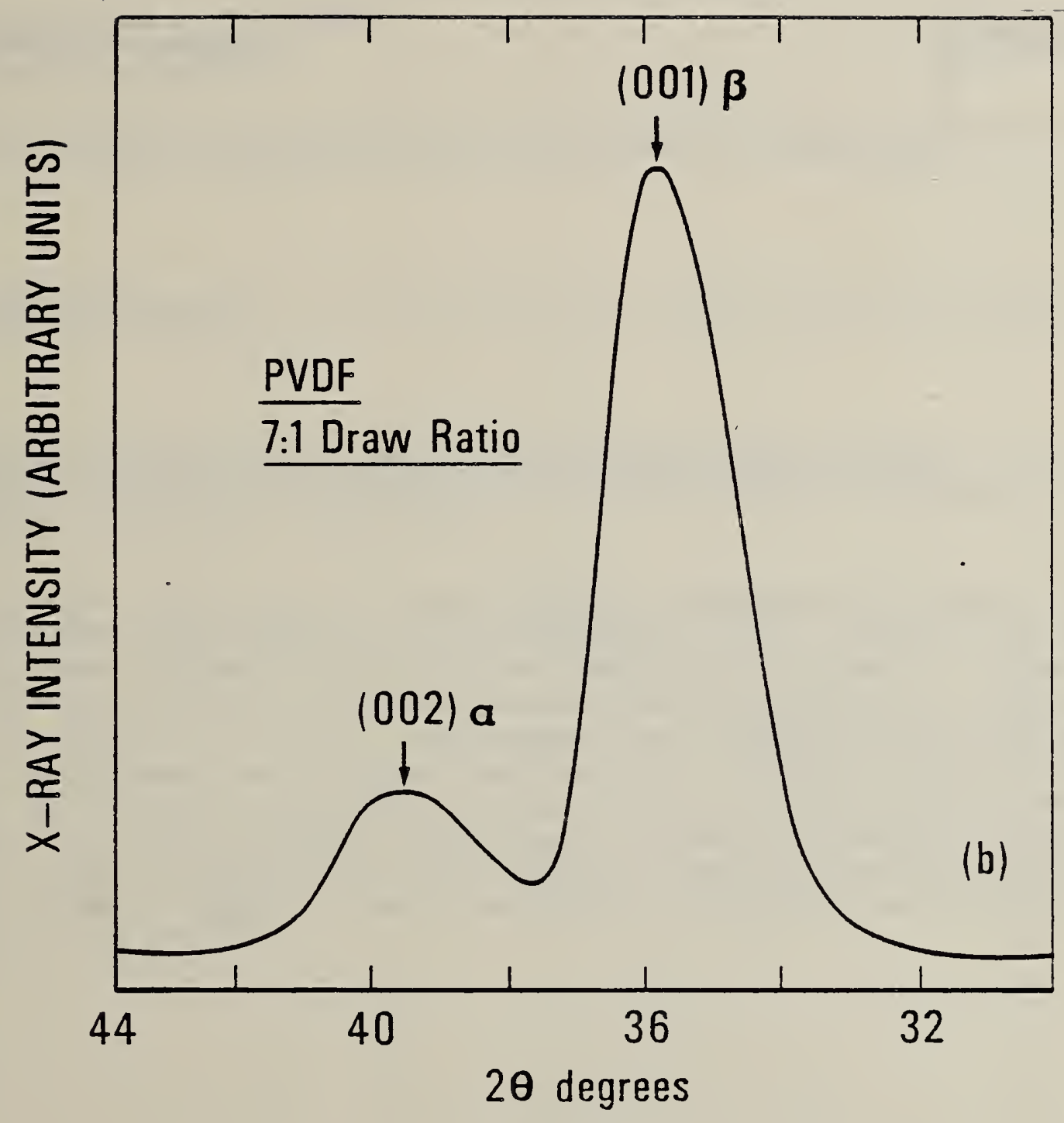

Figure $5(t)$ 

NBS.114A (REV. 2-8C)

U.S. DEPT. OF COMM.

BIBLIOGRAPHIC DATA

SHEET (See in struction s)

4. TITLE AND SUBTITLE 1. PUBLICATION OR
REPORT NO.

NBSIR $81-2418$

\section{"Fabrication of UTtra-Drawn Thick PVDF Transducers"}

5. AUTHOR(S)
A.J. Bur and A.K. Tsao

6. PERFORMING ORGANIZATION (If joint or other than NBS, see instructions)

7. Contract/Grant No.

NATIONAL BUREAU OF STANDARDS

DEPARTMENT OF COMMERCE

WASHINGTON, D.C. 20234

8. Type of Report \& Period Coverec

9. SPONSORING ORGANIZATION NAME AND COMPLETE ADDRESS (Street. City. StOte, ZIP)

10. SUPPLEMENTARY NOTES

Document describes a computer program; SF-185, FIPS Software Summary, is attached.

11. ASSTRACT (A 200-word or less foctual summary of most significant information. If document includes a significant bibliogrophy or literoture survey, mention it here)

Ultra-drawn PVDF (polyvinylidene fluoride) transducers have been fabricated from pellet resin material with thicknesses of $0.23,0.30$ and $0.50 \mathrm{~mm}$. The samples were mechanically ultra-drawn beyond their natural 4:1 draw ratio to a 7:1 ratio in order to enhance the molecular orientation and thereby optimize the piezoelectric activity. The samples were characterized using modulus and $x$-ray measurements which showed that modulus increases with increasing draw ratio and that the crystalline portion of the $7: 1$ drawn material was mostly $B$ phase. Ten out of fourteen samples were successfully poled at room temperature with fields ranging from 1.6 to $2.5 \mathrm{MV} / \mathrm{cm}$. The pyroelectric activities ranged from 2.0 to $4.1 \frac{\mathrm{ne}}{\mathrm{cm}^{2} \mathrm{~K}}$ and the hydrostatic piezoelectric coefficients ranged from 8.6 to $15.6 \mathrm{pC} / \mathrm{N}$.

12. KEY WORDS (Six to twelve entries; alphabetical order; capitalize only prober nomes; and separate key words by semicolons) Draw ratio; modulus; orientation; piezoelectricity; poly(vinylidene fluoride; pyroelectricity; ultra-drawn; $x$-ray

13. AVAILABILITY

Х Unlimited

For Official Distribution. Do Not Release to NTIS

Order From Superintendent of Documents, U.S. Government Printing Office, Washington, D.C. 20402.

14. NO. OF

FRINTED PAGES

X Order From National Technical Information Service (NTIS), Springfield, VA. 22161

24

15. Price 
